\title{
POSSESSION PHENOMENA IN WESTERN EUROPE: A CASE REPORT AND LITERATURE REVIEW
}

Aymerich, C., Mancebo, G., Laría, I., Urruticoechea, I., Martínez, A., Andrés, L., Paniagua, A.1, Blanco, J., Gómez, D., Madrazo, A., Bustamante, S., González-Torres, MA.

Psychiatry Department. Hospital Universitario Basurto. Osakidetza, Bilbao (Spain)

\section{BACKGROUND}

Cultural diversity and its impact on mental health is an increasingly relevant issue in our daily practice. Clinicians increasingly treat patients from culturally and socially diverse backgrounds, with different expressions of discomfort. The beliefs and cultural background of our patients affect their perception of mental illness, their coping strategies and their treatment search patterns [1,2]. A better understanding of such phenomena reinforces therapeutic alliance, helps formulate more precise diagnosis, and improves therapeutic adherence [3]. We hereby present the case of a patient with a phenomenon of possession as the main nosological entity.

\section{CASE REPORT}

Introduction: 41-year-old woman from Bolivia. Single. Mother of a 19-year-old son. She was transferred to the emergency department because of a sudden onset behavior disturbance 12 hours ago. She reported having been possessed by the Holy Spirit and announced with great anguish the imminent arrival of the apocalypse. She had no relevant medical or psychiatric history, nor reported consumption of toxic substances.

Demographic data: The patient was born in a rural region of Bolivia. She recounted a childhood without significant trauma, becoming pregnant of his first and only son, with whose father he has no relationship, at 22. At 27 he moved to Spain for work reasons. At the time of migration, the patient did not have any family or friends in Spain. In Spain she works as a shop clerk, with good work performance. She belongs to the Evangelical Christian cult, and describes herself as a very religious and spiritual woman. All of her social circle in Spain is made up of other people belonging to her cult.

Current episode: As recounted by her son, the patient had aroused abruptly from sleep at approximately 5 AM. With fearful attitude, she said she had been possessed and announced the imminent arrival of the end of the world. She alternated between crying and unmotivated laughter and showed self-harming behavior, repeatedly hitting herself and surrounding objects. Her son took her to the church at around 8 AM, were the priest and the rest of the congregation prayed "to help her in her possession spell", as reported by the son. 8 hours later, in the absence of improvement, they decided to transfer her to the emergency department of the nearest hospital.

Examination: Upon initial examination, the patient was conscious, partially connected to the environment and poorly collaborative. She obeyed simple orders in a fluctuating manner, interspersing a sparse speech in words with laughter and unmotivated cries and constant verbalizations of a religious nature, with significant psychomotor agitation. Again, he referred to being possessed by the Holy Spirit. The complementary tests, including the toxic ones in urine, were completely normal. Hospital admission was decided.

Evolution: In the unit, the patient remained accompanied by her son and a congregation friend, who spent the following hours praying for their well-being. The patient presented a rapid improvement remaining behaviorally adequate with anxiolytic treatment. Two days later, she completely criticized the episode, referring to partial amnesia and spontaneously identifying her recent sentimental breakup as a possible trigger. At the time of discharge, she reported feeling "relieved" after the episode of possession. Her evolution has been positive, not requiring psychopharmacological treatment after discharge and having resumed her life without further incidence.

Diagnosis: Unspecified Dissociative Disorder [DSM-5 300.15]

\section{DISCUSSION}

The ritual elicitation of altered states of consciousness, particularly those associated with possession, is present in more than $\mathbf{4 5 0}$ societies in the world [4]. In Western societies, it is common among Evangelical Pentecostal, Charismatic Catholic and AfricanAmerican religions, and also among Spiritualist cults [5].

The term 'possession' denotes that an individual has been invaded by an alien spirit or other paranormal force, with significantly alters the actions and identity of the affected to a greater or lesser extent. It must be considered pathological when it occurs involuntarily and/or causes significant discomfort in those who suffer it or in their environment.

Abnormal spiritual experiences are frequent among the general population, and most are not due to a psychotic disorder [6]. The phenomenon of 'Possession' is considered the most common culture-bound psychiatric disorder. This view is not exempt from controversy either: some research suggests that it is a mostly dissociative disorder, and not really culture-bound [7].

In DSM-IV-TR, possession and trance were classified under Appendix B - Research Criteria for Dissociative Trance Disorder [8]. This edition of the manual, and in particular its 'Culture-Bound Syndromes' classification, received numerous criticisms for its universal approach to the classification and diagnosis of mental disorders. The DSM-5 has introduced some changes, emphasizing that culturally appropriate possession states should be distinguished from the dissociative identity disorder possession type.However, this binary view of possession continues to be excessively simplistic for many authors.

\section{CONCLUSIONS}

The states of possession are an entity described in most cultures and societies. Most of them are not related to a psychotic disorder When examining a patient suffering from a 'possession' state clinicians should consider all the biopsychosocial and cultural factors of the individual. A better understanding of cultural differences is crucial in mental health, because of its role in the perception and significance of symptoms, the diagnostic process, and the treatment prescription.

\section{SOURCES}

[1] Gopalkrishnan and Babacan, 2015.

[2] Nakkas, Annen and Brand, 2019

[3] De las Cuevas, Motuca, Baptista and Villasante-Tezanos, 2019.

[4] Bourguignon, 1973.

[5] Harding, 2005

[6] Moreira-Almeida and Cardeña, 2011.

[7] Ross, 2011.

[8] American Psychiatric Association, 2000 